\title{
Vibration Measurements on Dissolution Systems and Effects on Dissolution of Prednisone Tablets RS
}

\author{
Saroj Vangani ${ }^{1}$, Tawnya Flick, Germinia Tamayo, \\ Rick Chiu, and Nina Cauchon \\ Small Molecule Pharmaceutics, Amgen Inc., One Amgen Center Drive, M/S 8-1-C, Thousand Oaks, CA 91320
}

\begin{abstract}
Efforts are being made by various groups $(1,2)$ to focus more on mechanical calibration as a potential replacement for Prednisone tablets RS (calibrator tablets). Although some mechanical calibration is currently performed (e.g., wobble, centering), the PhRMA committee's original proposal was to replace the Prednisone tablets RS through use of enhanced mechanical calibration.

A collaborative study (3) executed by PhRMA members to determine the feasibility of this idea demonstrated that the results obtained from the Prednisone tablets are operationally sensitive to several critical bath parameters. In addition, it was found that insufficient information exists to establish a meaningful tolerance for vibration (4).

The present study was performed to collect vibration information using two commercially available vibration meters, VanKel QAll station and Balmac 200. Vibration measurements were taken under normal conditions and in the presence of perturbations (slight and forced) generated artificially using a vortexer and a Vorti-Siv mixer. The main objective of the study was to determine if the apparatus could meet the proposed 0.1-mil displacement tolerance limit at the centerline of the vessel plate, and to observe what level of vibration is associated with 0.2 -mil displacement.

In addition, the effect of vibration on the release of Prednisone from Prednisone tablets RS was also evaluated on three representative bath models:Varian VK-7000, Varian VK-7025, and Distek 2100B.
\end{abstract}

\section{Introduction}

here is only a brief mention in the USP of vibration requirements, consisting of the statement, "No part of the assembly, including the environment in which the assembly is placed, contributes significant motion, agitation, or vibration beyond that due to the smoothly rotating stirring element."Vibration is a complicated concept that can result in the addition of energy to a system. The addition of energy from an external source can alter the results of a dissolution evaluation. Such an alteration is an unacceptable source of error that must be minimized. It can be minimized by eliminating all external sources so that only the tester machinery is left as a potential vibration source that is external to the drug delivery system under evaluation.

Vibration is defined as "a periodic motion of particles of an elastic body or medium in alternately opposite directions from the position of equilibrium when that equilibrium has

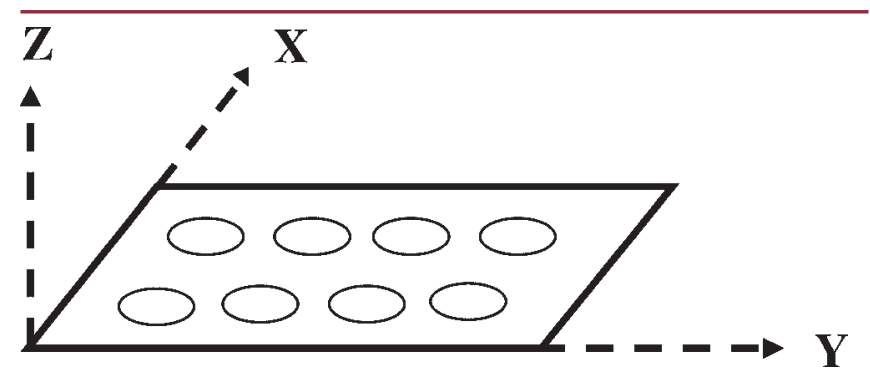

Figure 1. Frame of reference on dissolution baths for vibration measurements (5).

${ }^{1}$ Corresponding author. been disturbed." The energy (vibration) causing this movement is an interrelated function involving acceleration, velocity, displacement, and frequency (which can occur in three dimensions and can be designated $z, x$, and $y$ ). For the purpose of discussion, a frame of reference must be established. Using the vessel plate as a starting point, the $x$-axis will begin at the front left edge and go toward the back of the plate. This leaves the left-to-right vector as the $y$-axis and the up-and-down vector as the z-axis (Figure 1).

As a measure of vibration, displacement is often reported, since it is this relative motion that can be sensed by placing a hand on the tester. This is a measure of the up-and-down (in the $z$ axis) motion of the item of interest, in this instance, a dissolution tester. How often this up-and-down motion occurs is of equal importance, and this is the frequency. To measure one without the other does not provide sufficient information concerning the overall vibration. Vibrations of the same displacement but with differing frequency would not input the same amount of energy into a system over a given period of time. Frequency can be estimated based on eq 1.

$$
F=\frac{V}{D}
$$

where $\mathrm{F}$ is frequency, $\mathrm{V}$ is velocity, and $\mathrm{D}$ is displacement.

Common vibration meters display displacement in mils (which is an English unit that corresponds to $0.001 \mathrm{inch}$ ), velocity in inches/sec, and acceleration in units of gravity (g), which allows easier conversion between metric and common (English unit) values of velocity and displacement. 
Table 1. Vibration measurements in air using VanKel QAIl station $(n=3)$.

\begin{tabular}{|c|c|c|c|c|c|c|c|c|c|c|c|c|c|c|}
\hline Condi- & Bath & Model & Acc & eleratic & (g) & Fre & juency & $\mathrm{Hz}$ ) & & locity (ir & & Disp & cemer & (mil) \\
\hline & & & $x$ & $y$ & z & $x$ & $y$ & z & $x$ & $y$ & z & $x$ & $y$ & z \\
\hline Normal & \multirow{3}{*}{$\begin{array}{c}\text { VANKEL } \\
-1\end{array}$} & \multirow{3}{*}{$\begin{array}{c}\text { VK- } \\
7000\end{array}$} & 0.001 & 0.000 & 0.001 & 33.66 & 6.51 & 53.26 & 0.001 & 0.001 & 0.002 & 0.008 & 0.017 & 0.009 \\
\hline \begin{tabular}{|c|} 
Slight \\
Vibra- \\
tion
\end{tabular} & & & 0.001 & 0.000 & 0.001 & 76.47 & 67.34 & 61.96 & 0.001 & 0.001 & 0.002 & 0.008 & 0.017 & 0.009 \\
\hline \begin{tabular}{|c|} 
Forced \\
Vibra- \\
tion
\end{tabular} & & & 0.040 & 0.038 & 0.041 & 51.28 & 61.21 & 62.80 & 0.040 & 0.039 & 0.045 & 0.2 & 0.202 & 0.240 \\
\hline Normal & \multirow{3}{*}{$\begin{array}{c}\text { VANKEL } \\
-2\end{array}$} & \multirow{3}{*}{$\begin{array}{l}\text { VK- } \\
7025\end{array}$} & 0.000 & 0.000 & 0.000 & 0.000 & 6.01 & 0.000 & 0.000 & 0.0012 & 0.000 & 0.000 & 0.022 & 0.000 \\
\hline \begin{tabular}{|c|} 
Slight \\
Vibra- \\
tion
\end{tabular} & & & 0.012 & 0.016 & 0.010 & 54.88 & 46.75 & 21.98 & 0.0141 & 0.0223 & 0.0298 & 0.082 & 0.155 & 0.431 \\
\hline $\begin{array}{c}\text { Forced } \\
\text { Vibra- } \\
\text { tion }\end{array}$ & & & 0.034 & 0.016 & 0.029 & 41.80 & 40.12 & 40.62 & 0.0505 & 0.0259 & 0.0437 & 0.385 & 0.205 & 0.342 \\
\hline Normal & \multirow{3}{*}{$\begin{array}{c}\text { DISTEK } \\
-1\end{array}$} & \multirow{3}{*}{$2100 B$} & 0.009 & 0.000 & 0.000 & 86.68 & 0.000 & 0.000 & 0.0065 & 0.000 & 0.000 & 0.024 & 0.000 & 0.000 \\
\hline $\begin{array}{c}\text { Slight } \\
\text { Vibra- } \\
\text { tion }\end{array}$ & & & 0.012 & 0.011 & 0.007 & 58.80 & 54.85 & 39.68 & 0.0127 & 0.0126 & 0.0112 & 0.068 & 0.073 & 0.090 \\
\hline $\begin{array}{c}\text { Forced } \\
\text { Vibra- } \\
\text { tion }\end{array}$ & & & 0.021 & 0.011 & 0.011 & 41.20 & 45.79 & 32.64 & 0.0326 & 0.0149 & 0.0218 & 0.253 & 0.103 & 0.214 \\
\hline
\end{tabular}

This study was designed to evaluate the level of existing vibration on dissolution systems and to study and understand the effects of vibration on dissolution results.

Four studies were conducted using two commercially available vibration meters (Balmac 200 and a VanKel Technology Group QAll station). USP Apparatus 2 (paddle) was used as the stirring element in all the studies. All four studies were done on the baths available in our laboratory.

In the first study, vibrations were recorded on the vessel plate of dissolution testers under normal operation and with paddles rotating at $100 \mathrm{rpm}$ in air. Normal operation consists of paddles (at $100 \mathrm{rpm}$ ) with six vessels each containing $900 \mathrm{~mL}$ of water, with the heater circulator operating at a set water bath temperature of $37.5^{\circ} \mathrm{C}$.

A second vibration study was conducted with a source of vibration placed on the bench close to the dissolution tester, measuring below the PhRMA proposal of 0.2 -mil displacement.

A third vibration study was conducted with a source of vibration placed on the bench close to the dissolution tester, measuring close to or greater than the PhRMA proposal of 0.2 -mil displacement. Measurements were taken using the two vibration meters, and visual observations of any detectable ripple patterns in the media were made.

The fourth study targeted the impact of vibrations on the performance of Prednisone tablets RS using three representative bath models.

\section{Materials and Methods}

\section{Materials}

Prednisone tablets RS (10 mg, lot \# 00C056) and standard were obtained from USP.

\section{Methods}

Vibration measurements

Vibration information was collected using two different vibration meters (Balmac 200 and QAll station). The vibration measurements were made in $x, y$, and $z$ directions at the center of the vessel plate on three different baths, VK7000 
Table 2. Vibration measurements in water using VanKel QAII station $(n=3)$.

\begin{tabular}{|c|c|c|c|c|c|c|c|c|c|c|c|c|c|c|}
\hline \multirow[t]{2}{*}{$\begin{array}{l}\text { Condi- } \\
\text { tions }\end{array}$} & \multirow[t]{2}{*}{$\begin{array}{l}\text { Bath } \\
\text { Mfg }\end{array}$} & \multirow[t]{2}{*}{ Model } & \multicolumn{3}{|c|}{ Acceleration (g) } & \multicolumn{3}{|c|}{ Frequency $(\mathrm{Hz})$} & \multicolumn{3}{|c|}{ Velocity (in/s) } & \multicolumn{3}{|c|}{ Displacement (mil) } \\
\hline & & & $x$ & $y$ & $z$ & $x$ & $y$ & z & $x$ & $y$ & z & $x$ & $y$ & $z$ \\
\hline Normal & \multirow{3}{*}{$\begin{array}{c}\text { VANKEL } \\
-1 \\
\end{array}$} & \multirow{3}{*}{$\begin{array}{l}\text { VK- } \\
7000\end{array}$} & 0.000 & 0.000 & 0.001 & 0.000 & 0.000 & 49.39 & 0.000 & 0.000 & 0.0014 & 0.000 & 0.000 & 0.009 \\
\hline $\begin{array}{c}\text { Slight } \\
\text { Vibra- } \\
\text { tion }\end{array}$ & & & 0.009 & 0.004 & 0.001 & 94.20 & 103.66 & 54.95 & 0.0064 & 0.0025 & 0.0021 & 0.023 & 0.007 & 0.013 \\
\hline $\begin{array}{c}\text { Forced } \\
\text { Vibra- } \\
\text { tion }\end{array}$ & & & 0.016 & 0.013 & 0.073 & 74.95 & 72.80 & 59.45 & 0.0142 & 0.0117 & 0.0756 & 0.063 & 0.051 & 0.404 \\
\hline Normal & \multirow{3}{*}{$\begin{array}{c}\text { VANKEL } \\
-2 \\
\end{array}$} & \multirow{3}{*}{$\begin{array}{l}\text { VK- } \\
7025\end{array}$} & 0.000 & 0.000 & 0.000 & 0.000 & 0.000 & 0.000 & 0.000 & 0.000 & 0.000 & 0.000 & 0.000 & 0.000 \\
\hline $\begin{array}{c}\text { Slight } \\
\text { Vibra- } \\
\text { tion }\end{array}$ & & & 0.013 & 0.012 & 0.014 & 77.92 & 53.53 & 99.05 & 0.0112 & 0.0302 & 0.0092 & 0.045 & 0.044 & 0.031 \\
\hline $\begin{array}{c}\text { Forced } \\
\text { Vibra- } \\
\text { tion } \\
\end{array}$ & & & 0.008 & 0.017 & 0.014 & 23.18 & 27.84 & 23.25 & 0.0238 & 0.0394 & 0.0381 & 0.326 & 0.454 & 0.521 \\
\hline Normal & \multirow{3}{*}{$\begin{array}{c}\text { DISTEK } \\
-1 \\
\end{array}$} & \multirow{3}{*}{$2100 \mathrm{~B}$} & 0.000 & 0.000 & 0.000 & 0.000 & 0.000 & 0.000 & 0.000 & 0.000 & 0.000 & 0.000 & 0.000 & 0.000 \\
\hline $\begin{array}{c}\text { Slight } \\
\text { Vibra- } \\
\text { tion }\end{array}$ & & & 0.003 & 0.004 & 0.009 & 38.53 & 36.54 & 41.80 & 0.0053 & 0.0078 & 0.0139 & 0.043 & 0.068 & 0.105 \\
\hline $\begin{array}{c}\text { Forced } \\
\text { Vibra- } \\
\text { tion }\end{array}$ & & & 0.016 & 0.008 & 0.027 & 39.23 & 38.74 & 34.49 & 0.0267 & 0.0132 & 0.0488 & 0.217 & 0.108 & 0.450 \\
\hline
\end{tabular}

(VanKel-1),VK7025 (VanKel-2), and Distek 2100B (Distek-1). Measurements were taken in triplicate for the following three conditions, and the mean was reported:

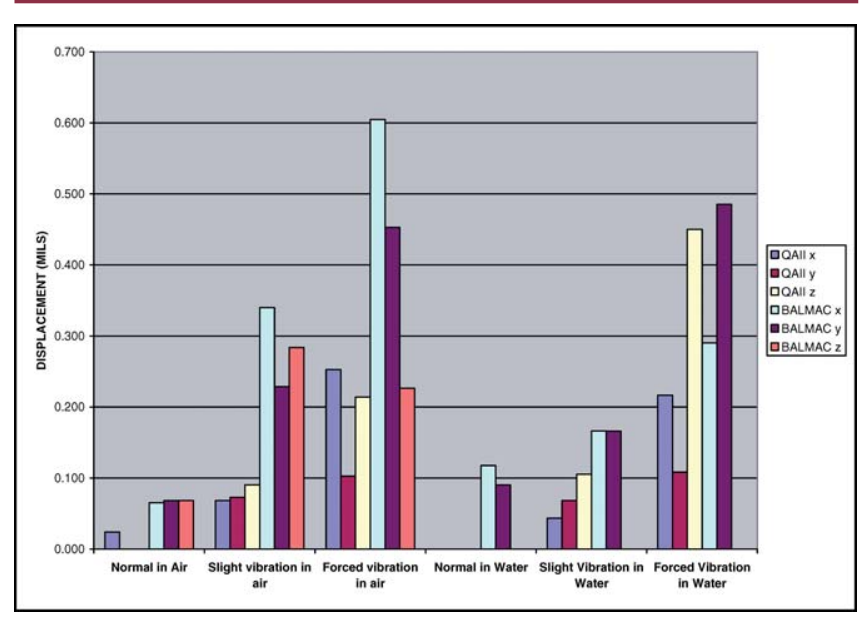

Figure 2. Displacement values for Distek $2100 \mathrm{~B}$ in $x, y$, and $z$ directions using Balmac 200 and VanKel QAll station in air and water. (a) Normal (No Vibration)

(b) Slight Vibration ( 0.1-mil displacement)

(c) Forced Vibration ( $\geq 0.2$-mil displacement)

Perturbations for slight vibration studies were accomplished by placing the VX2500 multiple vortexer (Speed 5) next to the dissolution bath, facing and touching the dissolution bath. Perturbations for forced vibration studies were accomplished by placing the Vorti-Siv next to the dissolution bath (this equipment did not have speed settings, hence the default settings were used).

\section{Vibration Measurements in Air}

Paddles were raised to the highest position above the dissolution plate and were set to rotate at $100 \mathrm{rpm}$. No dissolution medium was placed in the vessels. Measurements were taken in $\mathrm{x}, \mathrm{y}$, and $\mathrm{z}$ directions.

Note: Balmac 200 does not display frequency. Hence, the reported values for frequency are the calculated values (based on eq 1) determined from measured displacement and velocity (Tables 3 and 4). 
Table 3. Vibration measurements in air using Balmac $200(n=3)$.

\begin{tabular}{|c|c|c|c|c|c|c|c|c|c|c|c|c|c|c|}
\hline \multirow[t]{2}{*}{\begin{tabular}{|c} 
Condi- \\
tions \\
\end{tabular}} & \multirow[t]{2}{*}{$\begin{array}{l}\text { Bath } \\
\text { Mfg }\end{array}$} & \multirow[t]{2}{*}{ Model } & \multicolumn{3}{|c|}{ Acceleration (g) } & \multicolumn{3}{|c|}{ Frequency $(\mathrm{Hz})$} & \multicolumn{3}{|c|}{ Velocity (in/s) } & \multicolumn{3}{|c|}{ Displacement (mil) } \\
\hline & & & $x$ & $y$ & z & $x$ & $y$ & $z$ & $x$ & y & z & $\mathrm{x}$ & $y$ & z \\
\hline Normal & \multirow{3}{*}{\begin{tabular}{|c} 
VANKEL \\
-1 \\
\\
\end{tabular}} & \multirow{3}{*}{$\begin{array}{l}\text { VK- } \\
7000\end{array}$} & 0.004 & 0.005 & 0.006 & 69.616 & 61.728 & 58.789 & 0.004 & 0.005 & 0.006 & 0.035 & 0.044 & 0.058 \\
\hline \begin{tabular}{|c|} 
Slight \\
Vibra- \\
tion
\end{tabular} & & & 0.012 & 0.018 & 0.099 & 45.010 & 50.637 & 59.140 & 0.016 & 0.022 & 0.103 & 0.138 & 0.125 & 0.534 \\
\hline \begin{tabular}{|c|} 
Forced \\
Vibra- \\
tion \\
\end{tabular} & & & 0.125 & 0.152 & 0.420 & 77.160 & 97.522 & 63.181 & 0.100 & 0.096 & 0.411 & 0.771 & 0.621 & 1.995 \\
\hline Normal & \multirow{3}{*}{$\begin{array}{c}\text { VANKEL } \\
-2\end{array}$} & \multirow{3}{*}{$\begin{array}{c}\text { VK- } \\
7025\end{array}$} & 0.005 & 0.004 & 0.004 & 61.728 & 37.037 & 53.319 & 0.005 & 0.007 & 0.005 & 0.076 & 0.094 & 0.074 \\
\hline \begin{tabular}{|c|} 
Slight \\
Vibra- \\
tion
\end{tabular} & & & 0.028 & 0.009 & 0.018 & 34.339 & 29.181 & 34.014 & 0.050 & 0.018 & 0.033 & 0.711 & 0.288 & 0.405 \\
\hline $\begin{array}{c}\text { Forced } \\
\text { Vibra- } \\
\text { tion } \\
\end{array}$ & & & 0.037 & 0.031 & 0.065 & 42.295 & 29.745 & 39.337 & 0.054 & 0.064 & 0.102 & 0.440 & 0.531 & 0.727 \\
\hline Normal & \multirow{3}{*}{$\begin{array}{c}\text { DISTEK } \\
-1\end{array}$} & \multirow{3}{*}{$2100 B$} & 0.005 & 0.004 & 0.004 & 61.728 & 66.872 & 4.066 & 0.005 & 0.004 & 0.056 & 0.065 & 0.068 & 0.068 \\
\hline \begin{tabular}{|c|} 
Slight \\
Vibra- \\
tion \\
\end{tabular} & & & 0.028 & 0.019 & 0.022 & 41.642 & 41.394 & 39.017 & 0.042 & 0.028 & 0.035 & 0.340 & 0.229 & 0.284 \\
\hline $\begin{array}{c}\text { Forced } \\
\text { Vibra- } \\
\text { tion }\end{array}$ & & & 0.041 & 0.044 & 0.014 & 35.768 & 41.675 & 38.468 & 0.071 & 0.066 & 0.023 & 0.605 & 0.453 & 0.226 \\
\hline
\end{tabular}

\section{Vibration Measurements in Water}

Paddles were lowered into the dissolution vessels containing $900 \mathrm{~mL}$ of water and then maintained at $37^{\circ} \mathrm{C}$. The paddles were set to rotate at $100 \mathrm{rpm}$.

Notes: It was not feasible to take vibration measurements in $y$ and $z$ directions in water on VanKel 7025 (VanKel-2) using Balmac 200 vibration meter due to the design constraints.

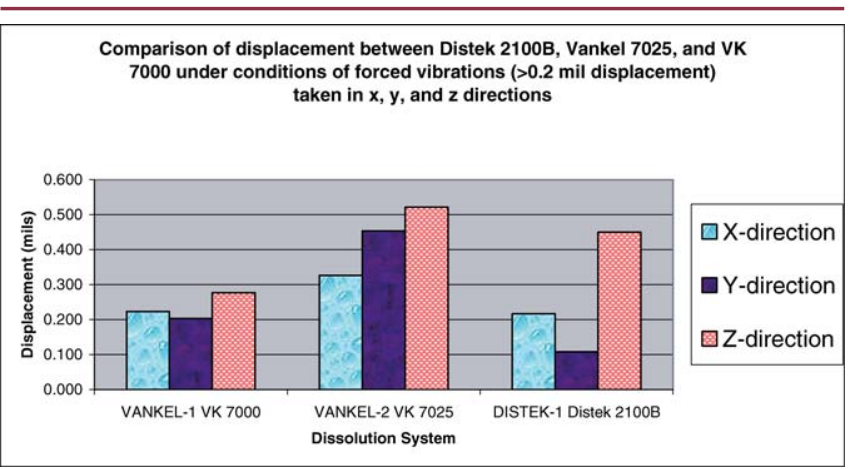

Figure 3. Comparison of displacement values between three bath models (Distek 2100B, VK 7000, and VK 7025) measured during conditions of forced vibrations using QAll station with the stirring units in water.
Hence, no results were reported for the same (Table 4).

Vibration measurements with the stirring elements in water involved lowering the drive unit. For some measurements, the vibration meters had to be placed between the drive unit and the vessel plate. Because of this, the paddles were slightly above the 2.5-cm USP specified limit from the bottom of the vessel for VK 7025 (VanKel-2) while taking the measurements.

\section{Evaluation of the Impact of Forced Vibrations on Dissolution}

The effect of vibration on the dissolution of Prednisone tablets was evaluated on three representative bath models, VK7000, VK7025, and Distek 2100B. Dissolution of Prednisone tablets was performed according to the USP procedure (50 rpm, USP Apparatus 2,30 minutes, $900 \mathrm{~mL}$ of deaerated water at $37^{\circ} \mathrm{C}$ ).

Two sets of dissolution experiments were conducted using the Prednisone tablets RS $(n=6)$, one under existing conditions (normal) and one under forced vibration conditions. Vibration measurements were taken in triplicate during the dissolution run, and the mean was reported. 
Table 4. Vibration measurements in water using Balmac 200 ( $n=3)$.

\begin{tabular}{|c|c|c|c|c|c|c|c|c|c|c|c|c|c|c|}
\hline \multirow[t]{2}{*}{$\begin{array}{l}\text { Condi- } \\
\text { tions }\end{array}$} & \multirow[t]{2}{*}{$\begin{array}{l}\text { Bath } \\
\text { Mfg }\end{array}$} & \multirow[t]{2}{*}{ Model } & \multicolumn{3}{|c|}{ Acceleration (g) } & \multicolumn{3}{|c|}{$\begin{array}{l}\text { Frequency (Hz)- } \\
\text { Calculated }\end{array}$} & \multicolumn{3}{|c|}{ Velocity (in/s) } & \multicolumn{3}{|c|}{ Displacement (mil) } \\
\hline & & & $x$ & $y$ & z & $x$ & $y$ & z & $x$ & $y$ & z & $x$ & $y$ & z \\
\hline Normal & \multirow{3}{*}{$\begin{array}{c}\text { Vankel- } \\
1\end{array}$} & \multirow{3}{*}{$\begin{array}{c}\text { VK700 } \\
0\end{array}$} & 0.008 & 0.008 & 0.008 & 67.240 & 50.526 & 39.879 & 0.007 & 0.009 & 0.012 & 0.069 & 0.097 & 0.059 \\
\hline $\begin{array}{c}\text { Slight } \\
\text { Vibra- } \\
\text { tion }\end{array}$ & & & 0.052 & 0.023 & 0.056 & 73.050 & 112.140 & 63.641 & 0.044 & 0.013 & 0.054 & 0.228 & 0.124 & 0.300 \\
\hline $\begin{array}{c}\text { Forced } \\
\text { Vibra- } \\
\text { tion } \\
\end{array}$ & & & 0.040 & 0.075 & 0.231 & 73.269 & 85.892 & 69.124 & 0.034 & 0.054 & 0.206 & 0.209 & 0.370 & 1.067 \\
\hline Normal & \multirow{3}{*}{$\begin{array}{c}\text { Vankel- } \\
2\end{array}$} & \multirow{3}{*}{$\begin{array}{c}\text { VK702 } \\
5\end{array}$} & 0.004 & $\mathrm{n} / \mathrm{a}$ & $n / a$ & 39.193 & $\mathrm{n} / \mathrm{a}$ & $\mathrm{n} / \mathrm{a}$ & 0.006 & $\mathrm{n} / \mathrm{a}$ & $\mathrm{n} / \mathrm{a}$ & 0.111 & $\mathrm{n} / \mathrm{a}$ & $\mathrm{n} / \mathrm{a}$ \\
\hline \begin{tabular}{|c|} 
Slight \\
Vibra- \\
tion
\end{tabular} & & & 0.017 & $n / a$ & $\mathrm{n} / \mathrm{a}$ & 24.187 & $n / a$ & $\mathrm{n} / \mathrm{a}$ & 0.043 & $n / a$ & $n / a$ & 0.785 & $\mathrm{n} / \mathrm{a}$ & $\mathrm{n} / \mathrm{a}$ \\
\hline $\begin{array}{c}\text { Forced } \\
\text { Vibra- } \\
\text { tion }\end{array}$ & & & 0.018 & $n / a$ & $\mathrm{n} / \mathrm{a}$ & 50.586 & $n / a$ & $\mathrm{n} / \mathrm{a}$ & 0.022 & $\mathrm{n} / \mathrm{a}$ & $n / a$ & 0.201 & $\mathrm{n} / \mathrm{a}$ & $\mathrm{n} / \mathrm{a}$ \\
\hline Normal & \multirow{3}{*}{$\begin{array}{c}\text { Distek- } \\
1\end{array}$} & \multirow{3}{*}{$2100 B$} & 0.006 & 0.006 & $\mathrm{n} / \mathrm{a}$ & 76.132 & 44.582 & $\mathrm{n} / \mathrm{a}$ & 0.005 & 0.008 & $\mathrm{n} / \mathrm{a}$ & 0.118 & 0.090 & $\mathrm{n} / \mathrm{a}$ \\
\hline $\begin{array}{c}\text { Slight } \\
\text { Vibra- } \\
\text { tion }\end{array}$ & & & 0.018 & 0.008 & $n / a$ & 53.792 & 49.944 & $\mathrm{n} / \mathrm{a}$ & 0.021 & 0.010 & $\mathrm{n} / \mathrm{a}$ & 0.166 & 0.166 & $n / a$ \\
\hline $\begin{array}{c}\text { Forced } \\
\text { Vibra- } \\
\text { tion }\end{array}$ & & & 0.025 & 0.021 & $\mathrm{n} / \mathrm{a}$ & 45.415 & 26.514 & $\mathrm{n} / \mathrm{a}$ & 0.034 & 0.050 & $\mathrm{n} / \mathrm{a}$ & 0.290 & 0.485 & $\mathrm{n} / \mathrm{a}$ \\
\hline
\end{tabular}

Note: It was not feasible to take vibration measurements in y and z directions in water on VanKel 7025 (VanKel-2) and Distek 2100B (Distek-1) using Balmac 200 vibration meter due to the design constraints. Hence, no results have been reported for the same in Table 4.

\section{Results and discussion}

\section{Vibration Measurements Using VanKel QAll Station}

Table 1 displays the vibration measurements taken in air, and Table 2 displays the measurements in water on various dissolution baths using the VanKel QAll station vibration meter.

It is clear from Tables 1 and 2 that the displacement, velocity, acceleration, and frequency values for all the baths were much lower in the presence of water than in air, particularly for measurements under normal conditions.

For measurements with stirring elements in water (Table 2), all baths showed comparable values (close to zero) in all directions and under all vibration conditions: normal, slight, and forced.

The effect of slight and forced vibrations was quite significant on the frequency measurements as compared to the displacement, velocity, or acceleration measurements.
As is clear from the displacement values ( $x, y$, and $z$ direction) taken with stirring elements in water (Table 2), the VK 7000 bath was least impacted by forced vibrations. The high frequency values (see section"Relationship Between

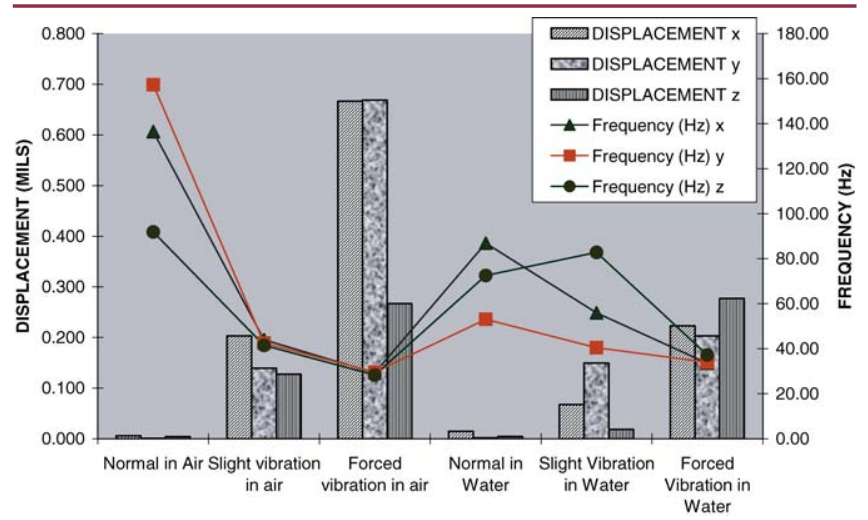

Figure 4. Frequency versus displacement relationship on VK 7000 using QAll station. 
Table 5a. Percent release of Prednisone under normal conditions and under forced vibration conditions on VK7000.

\begin{tabular}{|c|c|c|c|}
\hline Vessel & $\begin{array}{c}\text { \% Dissolved } \\
\text { (with } \\
\text { Vibration) }\end{array}$ & $\begin{array}{c}\text { \% Dissolved } \\
\text { (Normal) }\end{array}$ & $\begin{array}{c}\text { Pass with } \\
\text { Vibration }\end{array}$ \\
\hline 1 & 80 & 37 & NO \\
\hline 2 & 76 & 37 & NO \\
\hline 3 & 62 & 31 & NO \\
\hline 4 & 67 & 33 & NO \\
\hline 5 & 88 & 33 & NO \\
\hline 6 & 83 & 31 & \\
\hline Mean & 76 & 34 & \\
\hline SD $( \pm)$ & 9.9 & 2.7 & \\
\hline
\end{tabular}

Displacement and Frequency") for this bath under this condition confirmed the results.

\section{Vibration Measurements Using Balmac 200}

Table 3 displays the vibration measurements taken in air, and Table 4 displays the measurements in water on various dissolution baths using the Balmac 200 vibration meter.

It is clear from Tables 3 and 4 that the displacement, frequency, acceleration, and velocity measurement values in air and water were not significantly different for all the baths.

All measurements values (displacement, velocity, acceleration, and frequency) for forced vibration measurements on the VK 7000 bath (Table 3) indicate that this bath model was most impacted by the forced vibrations in air. No such conclusion could be made for other baths due to insufficient measurements in water.

\section{Comparison of Balmac 200 and VanKel QAll Station in Terms of Displacement}

It is clear from Tables 1-4 that all vibration measurements made using the Balmac 200 were much higher than those measured with the QAll station, particularly under normal conditions. For the forced vibration conditions, the

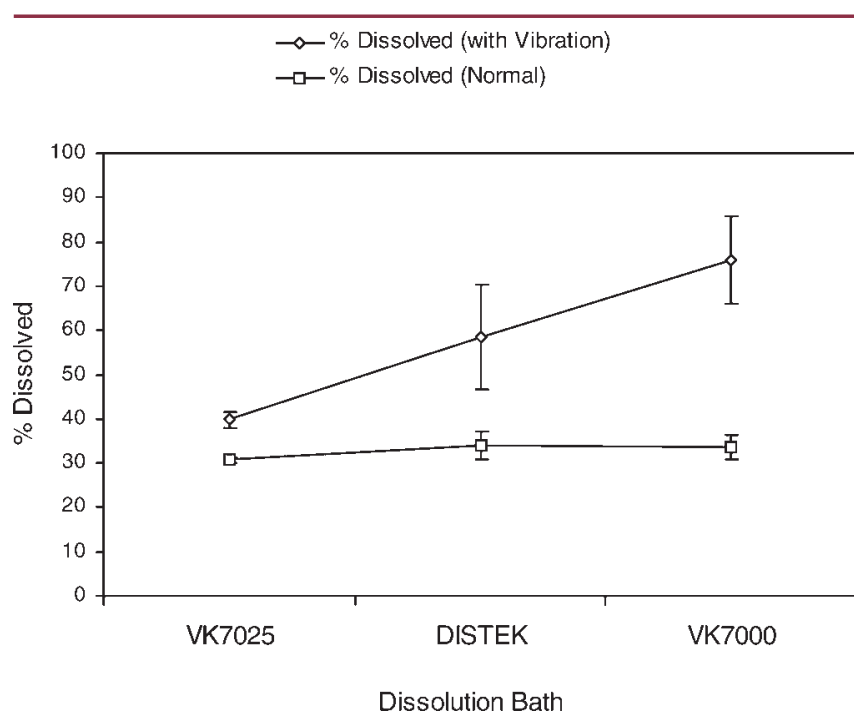

Figure 5. Dissolution data of Prednisone tablets at normal conditions and under forced vibration

frequency values for the two vibration meters were not significantly different. The reason for the high vibration measurements for the Balmac 200 could be because of the high background noise associated with this vibration meter which led to large fluctuations and higher readings than for the VanKel QAll station. The handling of the Balmac 200 meter was more critical than for the QAll station.

Figure 2 is the graphical comparison of displacement values obtained in air and water using the two vibration meters on one of the baths, Distek 2100B (Distek-1). It is clear from the data that for both meters, there was an increase in the displacement values with an increase in vibration intensity (from external sources) in all directions ( $x, y$, and $z$ ). This was true for both air and water.

It is also evident from the graph that QAll station was more sensitive (better correlation between forced vibration and changes in displacement measurements) in the $z$ direction, whereas Balmac 200 was more sensitive in the $x$ direction for displacement-value measurements.

Figure 3 is a graphical display of the comparison of displacement values in three bath models, Distek 2100B, VK 7000, and VK 7025 measured using VanKel QAll Station in water during the forced vibration study.

Table 5b. Mean of triplicate vibration measurements that were taken during the experiment.

\begin{tabular}{|c|c|c|c|c|c|c|c|c|c|c|c|c|c|}
\hline \multirow{2}{*}{$\begin{array}{c}\text { Vibra- } \\
\text { tion } \\
\text { Meter }\end{array}$} & \multirow{2}{*}{$\begin{array}{c}\text { Pertur- } \\
\text { bation } \\
\text { (Y/N) }\end{array}$} & \multicolumn{3}{|c|}{ Acceleration (g) } & \multicolumn{3}{|c|}{ Frequency (Hz) } & \multicolumn{3}{|c|}{ Velocity (in/s) } & \multicolumn{3}{|c|}{ Displacement (mil) } \\
\hline & & $\mathrm{x}$ & $y$ & z & $x$ & y & z & $x$ & y & z & $x$ & $y$ & z \\
\hline QAIl & Y & 0.007 & 0.017 & 0.013 & 28.58 & 35.11 & 28.86 & 0.017 & 0.032 & 0.029 & 0.189 & 0.291 & 0.318 \\
\hline $\begin{array}{c}\text { Balmac } \\
200\end{array}$ & $\mathrm{Y}$ & 0.019 & 0.028 & 0.041 & 41.89 & 42.16 & 37.22 & 0.028 & 0.041 & 0.068 & 0.336 & 0.469 & 0.691 \\
\hline
\end{tabular}


Table 6a. Percent release of Prednisone under normal conditions and under forced vibration conditions on VK7025.

\begin{tabular}{|c|c|c|c|}
\hline Vessel & $\begin{array}{c}\text { \% Dissolved } \\
\text { (with } \\
\text { Vibration) }\end{array}$ & $\begin{array}{c}\text { \% Dissolved } \\
\text { (Normal) }\end{array}$ & $\begin{array}{c}\text { Pass with } \\
\text { Vibration }\end{array}$ \\
\hline 1 & 38 & 30 & YES \\
\hline 2 & 39 & 30 & YES \\
\hline 3 & 44 & 30 & YES \\
\hline 4 & 39 & 30 & YES \\
\hline 5 & 40 & 32 & YES \\
\hline 6 & 39 & 31 & YES \\
\hline Mean & 40 & 31 & \\
\hline SD $( \pm)$ & 2.1 & 0.8 & \\
\hline
\end{tabular}

It is evident from the graph that under conditions of forced vibrations, VK 7025 was most impacted in all directions as compared with the other bath models. Distek 2100 $B$ showed minimum displacement values in the y direction. X-direction values were comparable for VK 7000 (VanKel-2) and Distek 2100B bath models under the same conditions.

\section{Relationship between Displacement and Frequency}

Measurements on VK 7000 using VanKel QAll station show the existence of an inverse relationship between the displacement and frequency. It is evident from the graph in Figure 4 that forced vibrations, both in air and water, showed maximum displacement values but minimum frequency values. Similarly, for measurements under normal conditions, the displacement values were minimal in air and water, but the frequency values were at the maximum, confirming the existence of this inverse relationship.

Frequency is a measure of how often the displacement occurs. Vibrations of the same displacement, but with differing frequency, will input different amounts of energy into the system during a given period. Measurement of displacement without frequency does not provide sufficient information about the overall vibration.

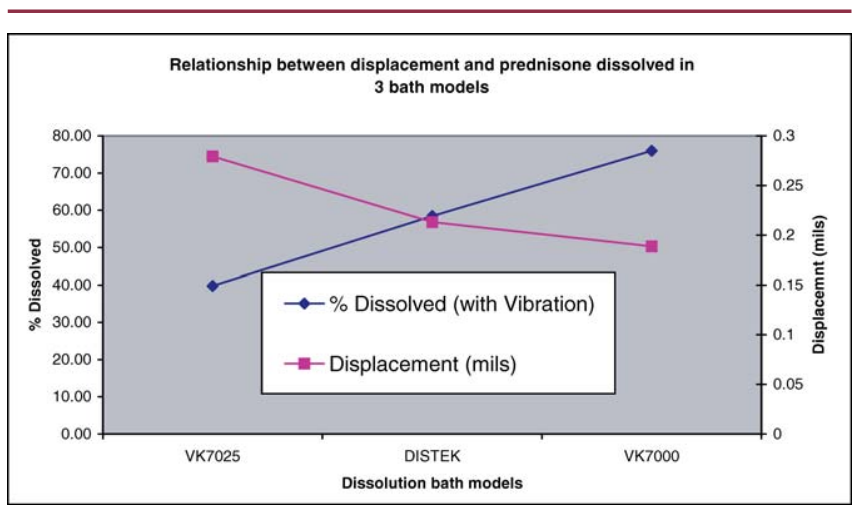

Figure 6. Relationship between displacement ( $x$ direction) values and percent release of Prednisone in three bath models in presence of forced vibrations.

\section{Dissolution Data on VanKel Dissolution Bath Model VK 7000}

Table 5a contains the dissolution data obtained on Prednisone tablets under normal conditions and in presence of forced vibrations on the VanKel VK 7000 dissolution bath. Table $5 \mathrm{~b}$ shows the mean of the triplicate vibration measurements taken using the two vibration meters during the actual run.

It is clear from Table 5 a that in presence of forced vibrations ( $\geq 0.2$ mil of displacement), all of the tablets failed to meet the USP limits (27-48\% of Prednisone dissolved in 30 $\mathrm{min}$ ). All tablets showed a significant increase in the percentage of Prednisone dissolved as compared with the USP limit.

\section{Dissolution Data on VanKel Dissolution Bath Model VK 7025}

Table 6a shows the Prednisone tablets RS dissolution data under normal conditions and in the presence of forced vibrations on VK 7025. The mean of the triplicate vibration measurements taken using the two vibration meters during the actual run is found in Table $6 \mathrm{~b}$.

It is clear from Table 6 a that in presence of forced vibrations ( $\geq 0.2$ mil of displacement), all tablets were within the USP limits (27-48\% of Prednisone dissolved in 30 minutes).

Table $6 \mathrm{~b}$. Mean of triplicate vibration measurements that were taken during the experiment.

\begin{tabular}{|c|c|c|c|c|c|c|c|c|c|c|c|c|c|}
\hline \multirow{2}{*}{$\begin{array}{l}\text { Vibra- } \\
\text { tion } \\
\text { Meter }\end{array}$} & \multirow{2}{*}{$\begin{array}{c}\text { Pertur- } \\
\text { bation } \\
\text { (Y/N) }\end{array}$} & \multicolumn{3}{|c|}{ Acceleration (g) } & \multicolumn{3}{|c|}{ Frequency (Hz) } & \multicolumn{3}{|c|}{ Velocity (in/s) } & \multicolumn{3}{|c|}{ Displacement (mil) } \\
\hline & & $x$ & $y$ & z & $x$ & y & z & $x$ & $y$ & z & $x$ & $y$ & z \\
\hline QAII & Y & 0.017 & 0.014 & 0.027 & 34.68 & 41.97 & 36.00 & 0.030 & 0.021 & 0.047 & 0.279 & 0.162 & 0.419 \\
\hline $\begin{array}{c}\text { Balmac } \\
200\end{array}$ & $Y$ & 0.041 & 0.050 & 0.080 & 37.34 & 42.68 & 36.55 & 0.068 & 0.072 & 0.136 & 0.583 & 0.614 & 1.412 \\
\hline
\end{tabular}


Table 7a. Percent release of Prednisone under normal conditions and under forced vibration conditions on Distek $2100 B$.

\begin{tabular}{|c|c|c|c|}
\hline Vessel & $\begin{array}{c}\text { \% Dissolved } \\
\text { (with } \\
\text { Vibration) }\end{array}$ & $\begin{array}{c}\text { \% Dissolved } \\
\text { (Normal) }\end{array}$ & $\begin{array}{c}\text { Pass with } \\
\text { Vibration }\end{array}$ \\
\hline 1 & 55 & 32 & NO \\
\hline 2 & 65 & 32 & NO \\
\hline 3 & 71 & 35 & NO \\
\hline 4 & 43 & 35 & YES \\
\hline 5 & 47 & 30 & YES \\
\hline 6 & 70 & 39 & NO \\
\hline Mean & 58 & 34 & \\
\hline SD $( \pm)$ & 12.0 & 3.2 & \\
\hline
\end{tabular}

\section{Dissolution Data on Distek Dissolution Bath Model 2100B}

Table 7a contains the dissolution data on Prednisone tablets under normal conditions and in the presence of forced vibrations on Distek 2100B. The mean of the triplicate vibration measurements taken using the two vibration meters during the actual run is found in Table $7 \mathrm{~b}$.

It is clear from Table 7a that in presence of forced vibrations ( $\geq 0.2$ mil of displacement), only two tablets were within the USP limits (27-48\% of Prednisone dissolved in 30 $\min )$.

\section{Relationship between Percentage Release of Prednisone and Displacement under Conditions of Forced Vibration}

Figure 5 is a graphical comparison of the performance of Prednisone tablets under normal conditions and in the presence of forced vibrations in three representative bath models. It is clear from the graph that the forced vibrations had the least effect on the VK7025 dissolution bath. This could also be the reason that all the Prednisone tablets RS passed on this dissolution system even in the presence of forced vibrations.

Figure 6 shows the relationship between the percentage of Prednisone dissolved and displacement (measured in $\mathrm{x}$ direction using QAII) in 3 bath models under conditions of forced vibration. It is clear from the graph that the percentage of Prednisone did not change significantly even in presence of forced vibrations on VK 7025 bath model.

It is evident from Tables $5 \mathrm{a}, 6 \mathrm{a}$, and $7 \mathrm{a}$ that forced vibrations caused both the percent release of Prednisone and the variability to shift towards higher values. For VK 7000, a $42 \%$ increase in the mean (from $34 \%$ to $76 \%$ ) was observed with more than tripling of the SD (2.7 to 9.9). For VK7025, a $9 \%$ shift in the mean (31\% to $40 \%$ ) and an almost tripling of the SD (0.8 to 2.1) were observed. For Distek 2100B, a $24 \%$ shift in the mean (34\% to $58 \%$ ) and more than tripling of SD (3.2 to 12) were observed. It is important to note that many of the perturbed-condition experimental data produced out-of-range results. Interestingly, the statistics also point to a similar change and, in this case, more consistently.

\section{Conclusion}

The two vibration meters, Vankel QAll and the Balmac 200, gave different responses. It is evident from the data on vibration measurements that Balmac 200 is more sensitive (larger fluctuations) than the Vankel QAll vibration meter. This may be because the meter has higher background noise, which leads to large signal fluctuations in the measurements. A proposed 0.1-mil displacement tolerance limit seems to be achievable with the VanKel QAll meter but not with the Balmac 200 meter. The design of the sensors could be one of the causes of the directional sensitivity to vibration.

From the vibration information collected, there does not seem to be trend between the displacement values and the direction of measurement $(x, y$, and $z$ orientation of the vibration meters). However, in most cases for both vibration meters, the displacement values in the $z$ direction were higher than those in the $x$ and $y$ directions. In addition, in most cases, vibration measurements in water were lower than in air.

Table $7 b$. Mean of triplicate vibration measurements that were taken during the experiment.

\begin{tabular}{|c|c|c|c|c|c|c|c|c|c|c|c|c|c|}
\hline \multirow{2}{*}{$\begin{array}{c}\text { Vibra- } \\
\text { tion } \\
\text { Meter }\end{array}$} & \multirow{2}{*}{$\begin{array}{c}\text { Pertur- } \\
\text { bation } \\
\text { (Y/N) }\end{array}$} & \multicolumn{3}{|c|}{ Acceleration (g) } & \multicolumn{3}{|c|}{ Frequency (Hz) } & \multicolumn{3}{|c|}{ Velocity (in/s) } & \multicolumn{3}{|c|}{ Displacement (mil) } \\
\hline & & $x$ & $y$ & z & $\mathrm{x}$ & y & z & $x$ & y & z & $x$ & y & $z$ \\
\hline QAll & Y & 0.019 & 0.004 & 0.005 & 42.76 & 40.99 & 37.92 & 0.028 & 0.008 & 0.009 & 0.213 & 0.063 & 0.073 \\
\hline $\begin{array}{c}\text { Balmac } \\
200\end{array}$ & Y & 0.014 & 0.018 & 0.099 & 46.28 & 55.82 & 38.41 & 0.019 & 0.020 & 0.161 & 0.163 & 0.177 & 1.208 \\
\hline
\end{tabular}


Based on the data, displacement should be measured in a consistent direction with a specified vibration meter that has been proven to meet the specific tolerance under normal conditions. The best way to mimic the vibration during a true dissolution run would be to measure the vibration while the vessels are filled with water.

Two vibration sources causing the same displacement but at different frequencies will input different amounts of energy to the system. This can have variable effect on the dissolution rate. Hence, simultaneous measurement of both frequency and displacement will better allow us to understand the overall vibration effects.

In the Prednisone study, forced vibrations ( $\geq 0.2-\mathrm{mil}$ displacement) resulted in a higher percentage of Prednisone dissolved in $30 \mathrm{~min}$. However, all tablets met the USP limits on Prednisone tablets RS on the VK 7025 bath model. This could be related to the design of this dissolution bath or be simply a function of this particular bath and its placement within the laboratory.

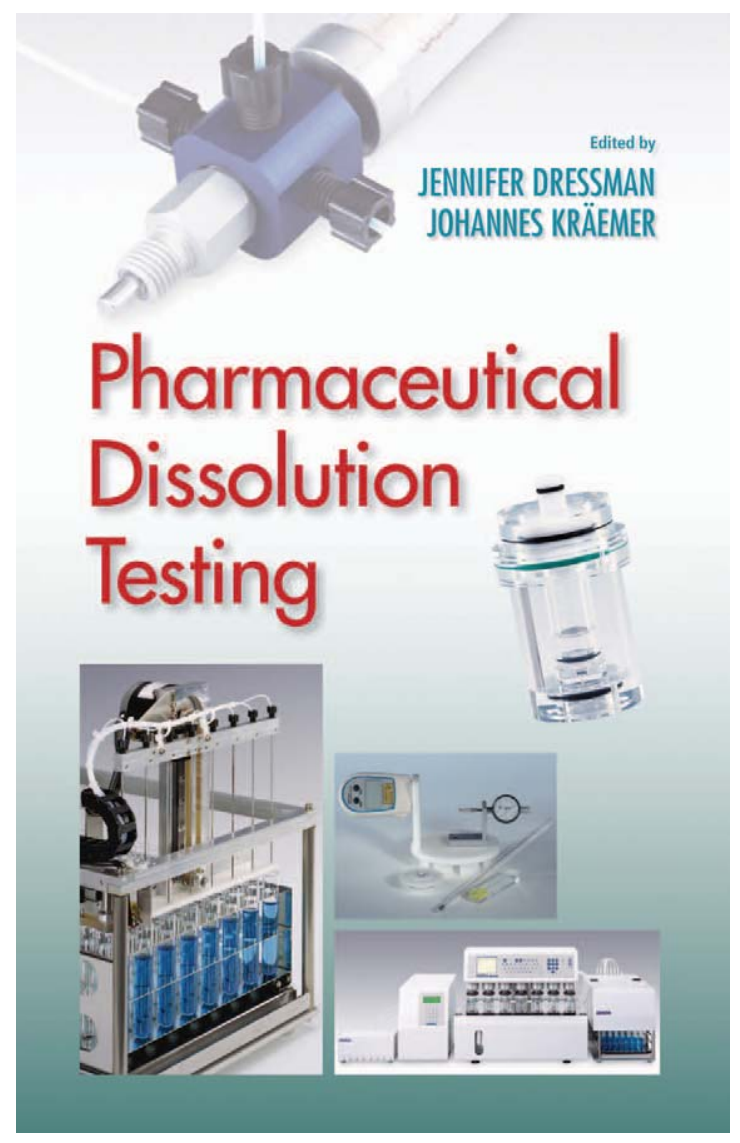

This book may be ordered online at the DT website at www.dissolutiontech.com. Price, including shipping, is $\$ 190.00$ for USA and $\$ 210.00$ for outside USA. Credit card payment is available.

\section{References}

1. Oates, M.; Brune, S.; Gray, V. A.; Hippeli, K.; Kentrup, A.; Whiteman, D. Dissolution Calibration:

Recommendations for Reduced Chemical Testing and Enhanced Mechanical Calibration. Pharm. Forum 2000, 26 (4), 1149-1166.

2. Crist, B.; Spisak, D. Evaluation of Induced Variance on the Calibrated USP Dissolution Apparatus 1 and 2. Dissolution Technol. 2005, 12 (1), 28-31.

3. Kaniwa, N.; Katori, N.; Aoyagi, N.; Ishigame, N. Collaborative study on the development of a standard for evaluation of vibration levels for dissolution apparatus. Int. J. Pharm. 1998, 175, 119-129.

4. Fujiwara, K.; Murashima, K.; Iwamoto, K.; Nishino, T. Influence of Equipment Vibration on Dissolution Rates. JP Forum 1997, 6 (1).

5. Collins, C. Vibration: What is it and How Might It Affect Dissolution Testing? Dissolution Technol. 1998, 5 (4), 16-18. 